\title{
Rock Mechanical Property Influenced by Inhomogeneity
}

\author{
Yunliang Tan, Dongmei Huang, and Ze Zhang \\ State Key Laboratory of Mine Disaster Prevention and Control, Shandong University of Science and Technology, \\ Shandong, Qingdao 266590, China \\ Correspondence should be addressed to Yunliang Tan, tylllp@163169.net
}

Received 26 March 2012; Revised 6 April 2012; Accepted 10 April 2012

Academic Editor: Amit Bandyopadhyay

Copyright () 2012 Yunliang Tan et al. This is an open access article distributed under the Creative Commons Attribution License, which permits unrestricted use, distribution, and reproduction in any medium, provided the original work is properly cited.

In order to identify the microstructure inhomogeneity influence on rock mechanical property, SEM scanning test and fractal dimension estimation were adopted. The investigations showed that the self-similarity of rock microstructure markedly changes with the scanned microscale. Different rocks behave in different fractal dimension variation patterns with the scanned magnification, so it is conditional to adopt fractal dimension to describe rock material. Grey diabase and black diabase have high suitability; red sandstone has low suitability. The suitability of fractal-dimension-describing method for rocks depends on both investigating scale and rock type. The homogeneities of grey diabase, black diabase, grey sandstone, and red sandstone are 7.8, 5.7, 4.4, and 3.4, separately; their average fractal dimensions of microstructure are 2.06, 2.03, 1.72, and 1.40 correspondingly, so the homogeneity is well consistent with fractal dimension. For rock material, the stronger brittleness is, the less profile fractal dimension is. In a sense, brittleness is an image of rock inhomogeneity in macroscale, while profile fractal dimension is an image of rock inhomogeneity in microscale. To combine the test of brittleness with the estimation of fractal dimension with condition will be an effective approach for understanding rock failure mechanism, patterns, and behaviours.

\section{Introduction}

Many investigations showed that rock failure patterns are related the inhomogeneity of rock microstructure [1-8]. In order to make clear the relations between rock failure patterns and rock microstructure, some detecting techniques such as scanning electron microscope (SEM), X-ray tomographic microscopy (XTM), laser speckle interferometry, secondary ion mass spectroscopy, and electron microscopy are used. For example, Nasseri et al. [9] observed the sawtooth structure of rock failure pattern by SEM. Raynaud et al. [10] adopted XTM and SEM to study the relations between hydraulic properties of clayey rocks. With the help of SEM, Alkan [11] presented a percolation model to predict the dilatancy-induced permeability in an excavation damaged zone of rocks salt.

Bearing this in mind, we firstly used the high-low vacuum scanning electron microscope named after JSM6510LV which was manufactured by the JEOL, to learn the microstructure of four type rocks: grey diabase, black diabase, grey sand stone, and red sandstone. We then analysed the relations between inhomogeneity of these rocks and the profile fractal dimensions and further investigated the relation between brittleness and rock profile fractal dimension $[8,12]$, so as to make better understanding of rock failure mechanism and patterns resulted from inhomogeneity.

\section{Methodology}

2.1. SEM Scanning. The scanning device is a new type of SEM called JSM-6510LV, which was manufactured by the JEOL. It consists of the following basic components: electron optics system, scanning system, signal detection amplification system, image display and record system, battery, and vacuum.

The experimental procedure was as follows: first, a $50.0 \mathrm{~mm}$ diameter borehole was drilled, and the boring sample was taken from the hole. Second, some standard specimens with $100 \mathrm{~mm}$ high and $50 \mathrm{~mm}$ wide were cut processed. Third, compressive test was carried out in RLJW2000 servo compression test machine. Fourth, the rock fragments were filled with nitrogen gas, with a pressure of 2 
bars, blew axially from the nozzle to protect the focusing lens and to assist the scanning process. Finally, the scanning work was carried out using a continuous wave and multimode $\mathrm{CO}_{2}$ laser with a maximum output power of $2 \mathrm{~kW}$. Laser parameters used in the experiment were as follows: laser power $1000 \mathrm{~W}$, beam size in diameter $4.0 \mathrm{~mm}$, and scanning velocity $8 \mathrm{~mm} / \mathrm{s}$. The focusing lens was protected by a coaxially flowing gas $\mathrm{N}_{2}$. The cross-sections or surfaces were characterized by SEM incorporating energy dispersive Xray analysis (EDX) using a JSM-6510LV scanning electron microscope.

2.2. Box-Counting Approach for Fractal Dimension. Fractal geometry popularized by Mandelbrot [13] has gained much support in the field of image analysis. From the properties of self-similarity, fractal dimension $D$ of a set $A\left(A \in R^{n}\right)$ defined by Pentland [14] is as follows:

$$
D=\lim _{r \rightarrow 0} \frac{\log N_{r}}{\log (1 / r)},
$$

where $N_{r}$ is the total number of distinct copies similar to $A$ and $A$ is scaled down by a ratio of $1 / r$. There are several approaches to estimate the fractal dimension for an image surface, such as reticular cell counting method [15], Keller's approach [16], and differential box-counting method [17]. In order to estimate the roughness effectively due to improper limits and box size, many authors have assumed certain bounds according the procedure adopted by them [18-20].

In this paper, the box counting approach suggested by Sarkar and Chaudhuri [21] was adopted. It is expressed as follows: suppose a three-dimensional image has $M \times M$ pixel and $G$ gray level progression, presenting in a form of $(x, y, z)$. The first dimension and the second dimension determine the position of a pixel in a two-dimensional image plane, the third dimension shows its gray scale. When reducing its scale to $S \times S(M / 2 \geq S>1, S$ is an integer) using a proportion factor of $r(r=S / M)$ in two-dimensional plane, the gray level is expressed by the third dimension. The volume of each box is $S \times S \times S^{\prime}$, where the new gray level progression $S$ meets

$$
\operatorname{int}\left(\frac{G}{S^{\prime}}\right)=\operatorname{int}\left(\frac{M}{S}\right)
$$

where $\operatorname{int}\left(G / S^{\prime}\right)$ is the minimum integer greater than $G / S, \operatorname{int}(M / S)$ is the minimum integer greater than $M / S$. The space of $M \times M$ is composed of a series boxes with the space of $S \times S$. Suppose that in an $i \times j$ area the minimum and maximum gray level grade is, respectively, dropped in the area of number $K$ and number $L$ box according to the new gray level progression, so the box quantity covered the $i \times j$ area is

$$
N_{r}(i, j)=L-K+1
$$

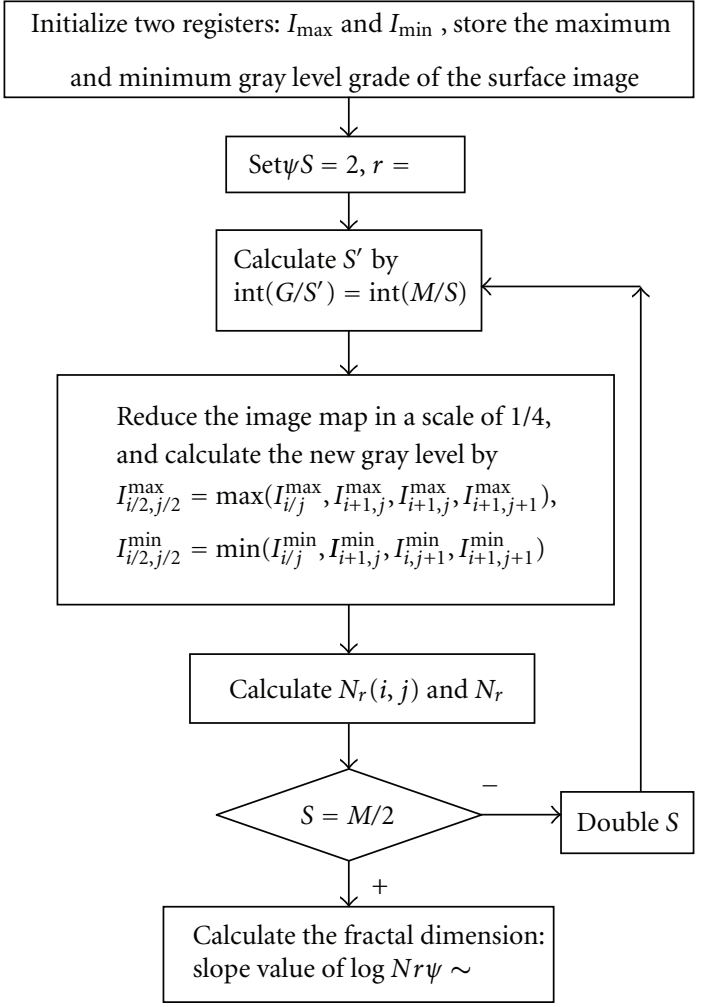

FIgURE 1: Flow chart for calculating fractal dimension.

The box count needed to cover the whole target object is

$$
N_{r}=\sum_{i, j}^{M} N_{r}(i, j) .
$$

By changing the scale $r$, we can obtain the different $N_{r}$ box count needed to cover the target object. At last, a diagram of $\log \left(N_{r}\right) \sim \log (1 / r)$ is drafted. Some research results [13$16,22,23]$ have shown that the mean square slope values of $\log \left(N_{r}\right)$ and $\log (1 / r)$ are suitable to be used to calculate the fractal dimension. It must be pointed out that $S=2 i$ should be used, where $i$ is an integer $(2 \leq S \leq M / 2)$ [24]. The procedure of calculation was demonstrated in Figure 1.

\section{Results and Discussion}

In order to estimate the different rock profile fractal dimension, we firstly obtained the images of four type rocks: black diabase, grey diabase, grey sandstone, and red sandstone; by using JSM-6510LV scanning electron microscope, the scanning amplification factor was 1000 . The microstructures of above four type rocks were obtained by SEM, as shown in Figure 2. In order to describe the inhomogeneity quantitatively, digital image processing (DIP) has been used $[25,26]$. The procedure is first to make the feature extraction from rock profile in digital. Secondly to obtain the shape and quantity of minerals. Again to classify mineral categories by the information of feature extraction. At last to obtain the 


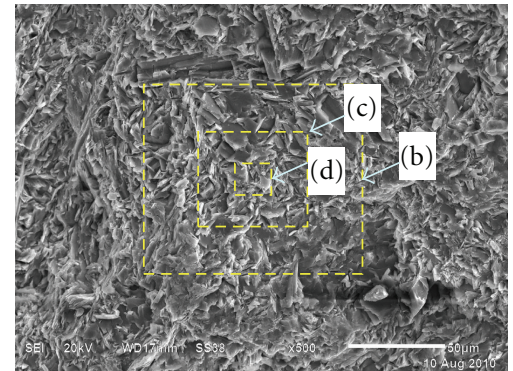

(a) Magnification 500

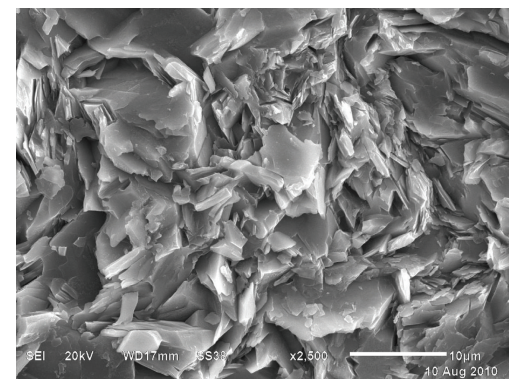

(c) Magnification 2500

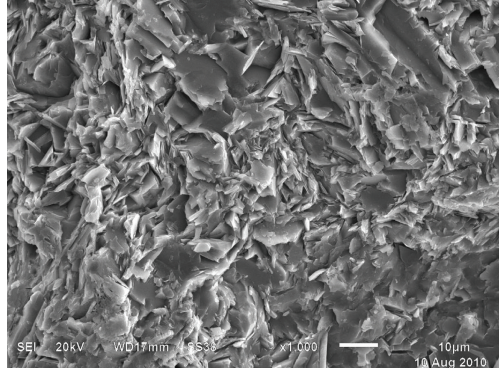

(b) Magnification 1000

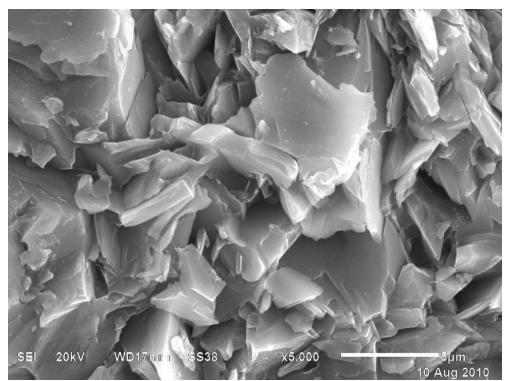

(d) Magnification 5000

Figure 2: SEM images of grey diabase with different magnifications.

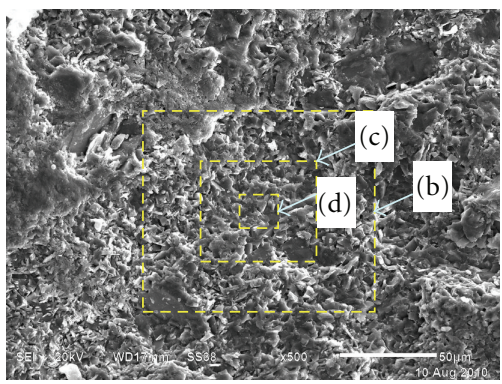

(a) Magnification 500

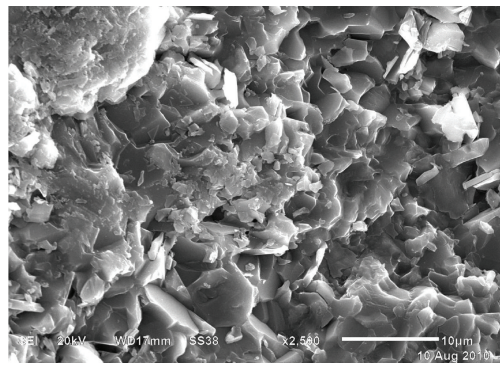

(c) Magnification 2500

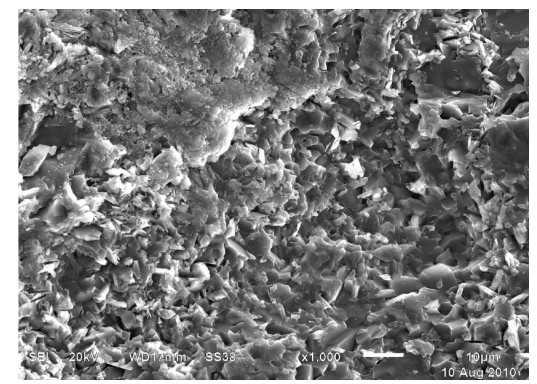

(b) Magnification 1000

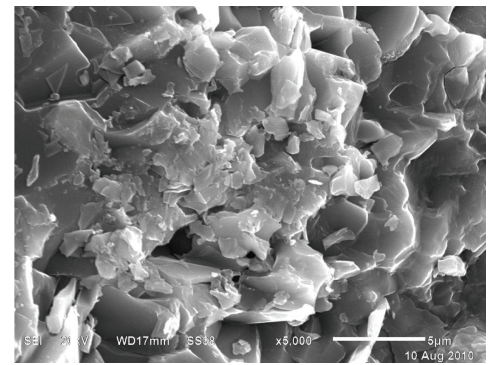

(d) Magnification 5000

FIGURE 3: SEM images of black diabase with different magnifications.

homogeneity of a rock. Previous work [27] indicated that the Weibull's function suits for describing the distribution of rock mechanical parameters. The homogeneous coefficient, $m$, was adopted in Weibull's distribution function:

$$
\varphi(u)=\frac{m}{g_{0}}\left(\frac{g}{g_{0}}\right)^{m-1} e^{-\left(g / g_{0}\right)^{m}}
$$

where $g$ is the strength of rock, $\varphi(g)$ is the density of distribution, $g_{0}$ is the average strength for all rock elements. Both $g$ and $g_{0}$ are indicated by grayscale easily in DIP. The coefficient, $m$, indicates homogeneous extent of rock material, that is, the larger value $m$ is, the more homogeneous material is.

We firstly obtained the SEM scanned images of above four kind stones with magnification 500. We then easily 


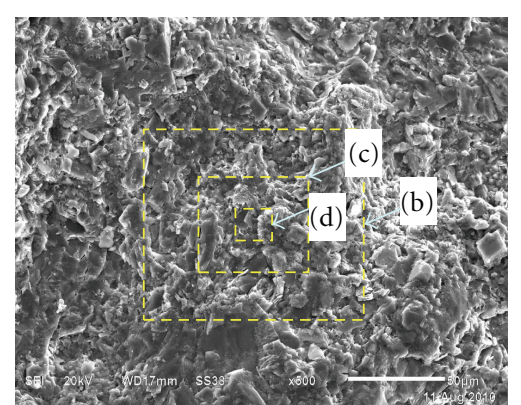

(a) Magnification 500

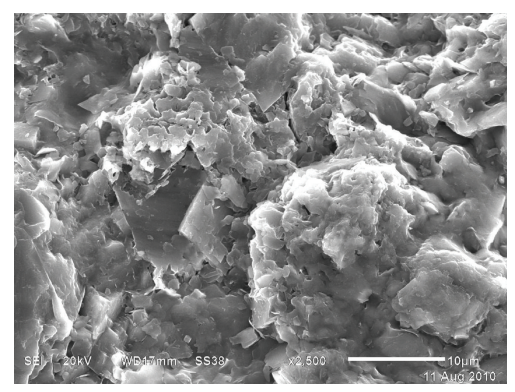

(c) Magnification 2500

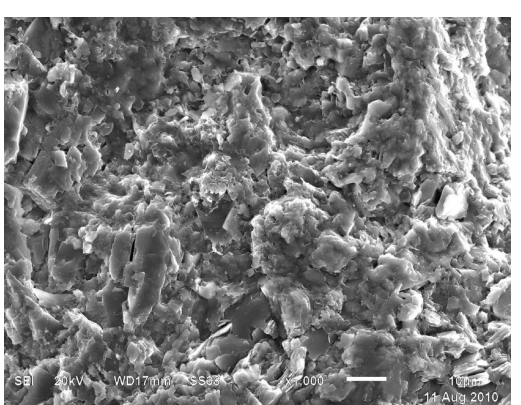

(b) Magnification 1000

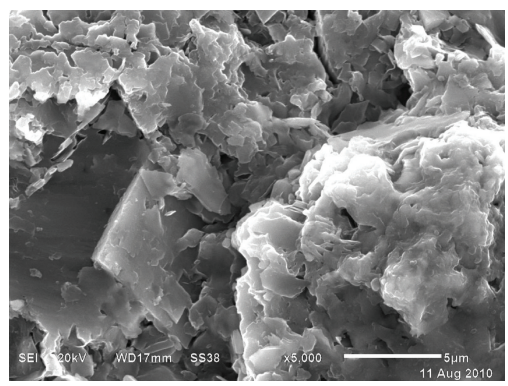

(d) Magnification 5000

FIGURE 4: SEM images of grey sandstone with different magnification.

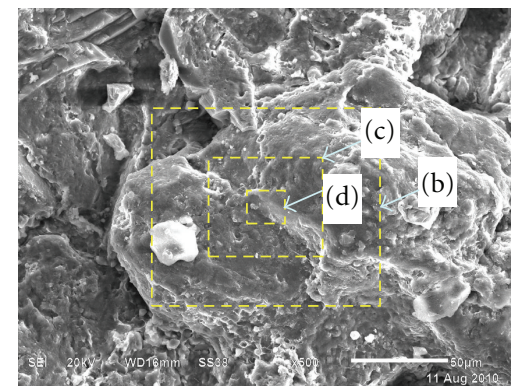

(a) Magnification 500

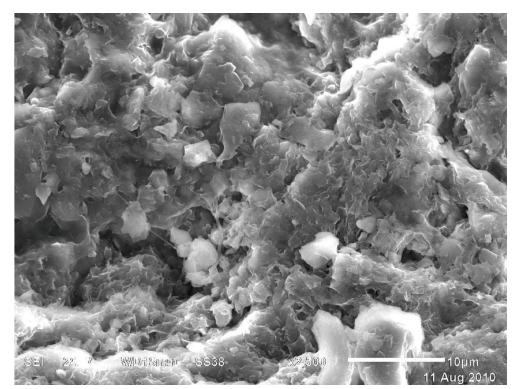

(c) Magnification 2500

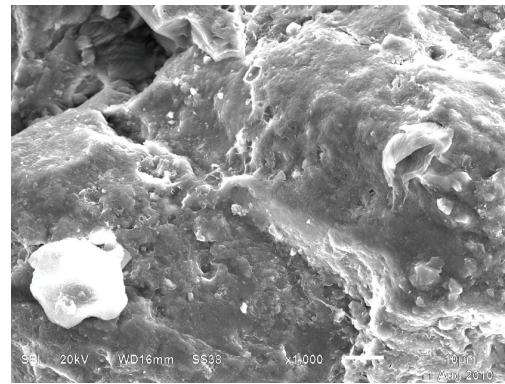

(b) Magnification 1000

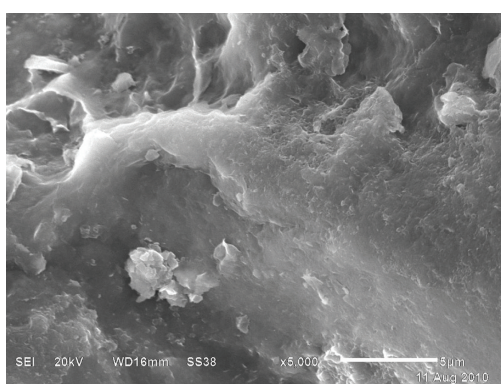

(d) Magnification 5000

FIGURE 5: SEM images of red sandstone with different magnification.

used DIP method and formula (5) to obtain the efficient $m$ of above four kind stones as 7.8, 5.7, 4.4, and 3.4, correspondingly.

In order to investigate the self-similarity of rock microstructure in different microscales, we obtained the SEM scanned images with four magnifications: 500, 1000, 2500, and 5000 in centre region of a sample, as shown in
Figures 2, 3, 4, and 5. Then box-counting approach for fractal dimension as shown in Figure 1 was performed. In this procedure, the linear fitting method was adopted. For example, the fractal dimensions and correlation coefficients of grey diabase with different microscales were easily obtained by this way, as shown in Figures 6 and 7. The fitted results of all above four type stones were listed in Table 1. 


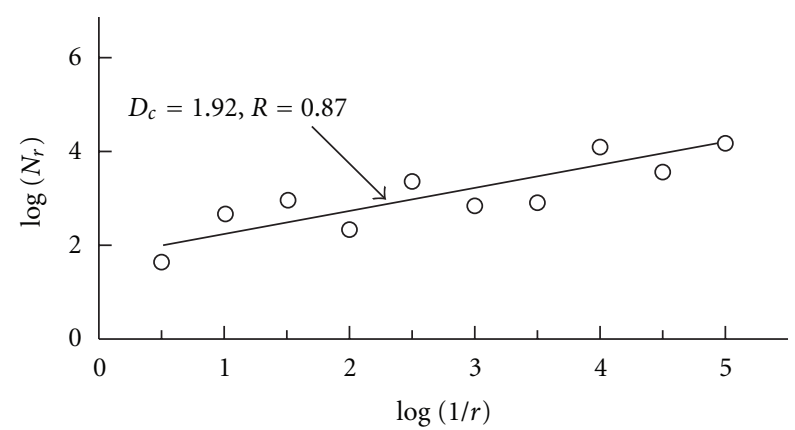

(a) Magnification 500

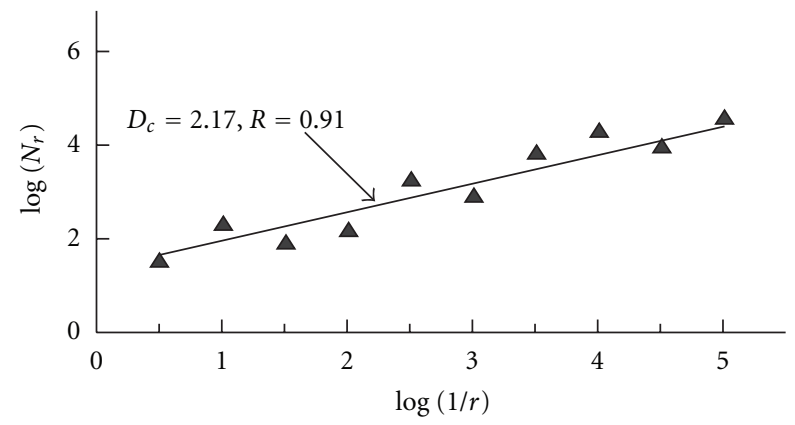

(c) Magnification 2500

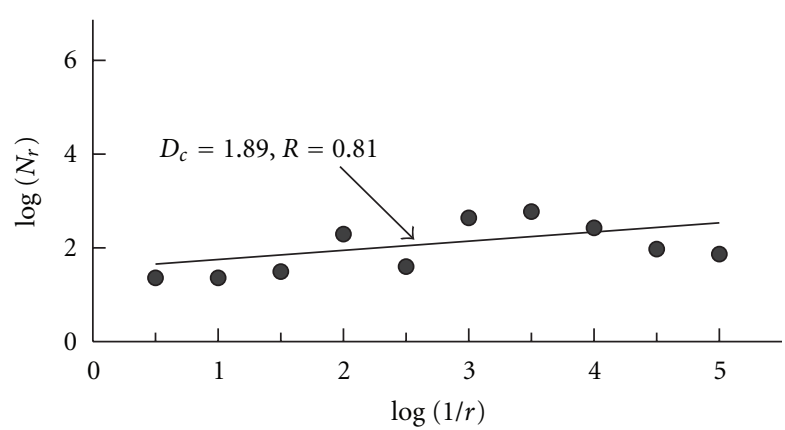

(b) Magnification 1000

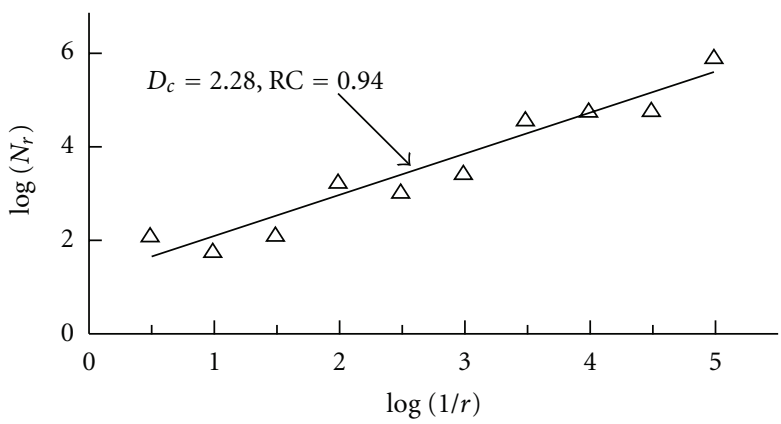

(d) Magnification 5000

Figure 6: Fitted $D_{c}$ of grey diabase for different magnification.

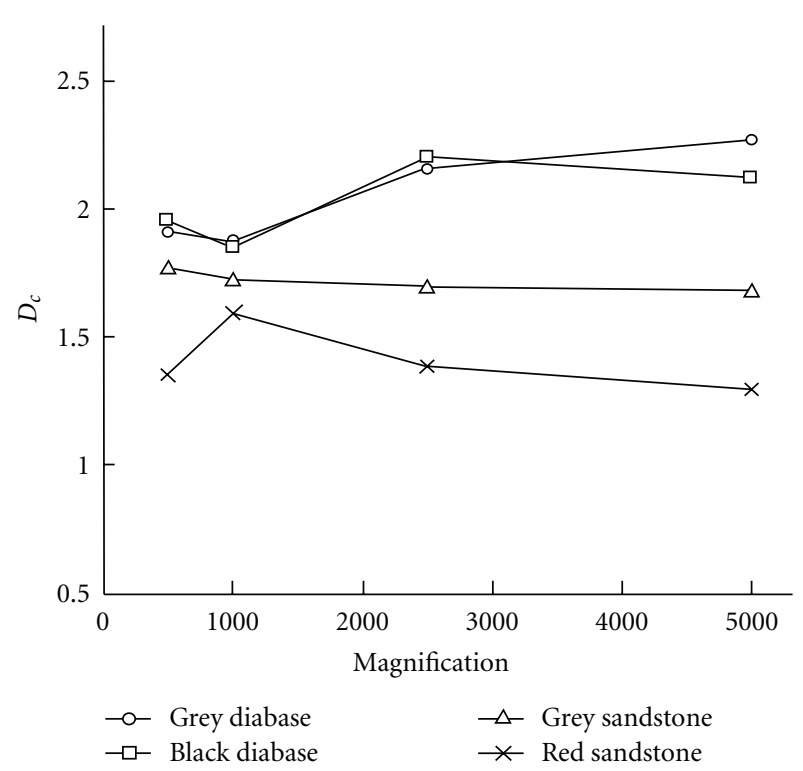

Figure 7: $D_{c}$ variation with magnification.

We found that diabase and black diabase have the same fluctuation pattern of "high-low-high" (Figure 7); that is, when magnification is 500, their fractal dimensions are 1.92 and 1.95 separately; when magnification reaches 1000 , their fractal dimensions decrease to 1.87 and 1.82 separately; when magnification is 2500, their fractal dimensions increase to 2.17 and 2.2; when magnification increases to 5000, their fractal dimensions are 2.28 and 2.12. Grey sandstone has a

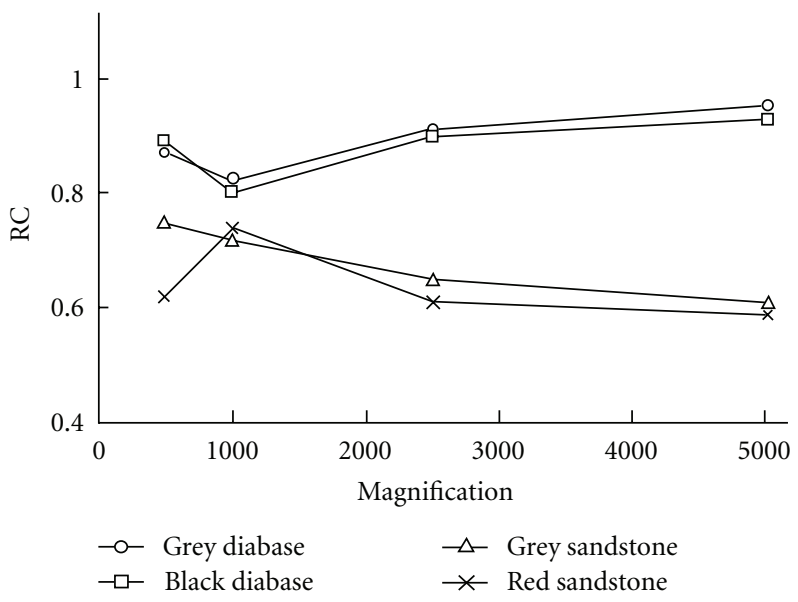

FIGURE 8: RC variation with magnification.

decreasing pattern, that is, when magnification varies from $500,1000,2500$ to 5000 , its fractal dimension decreases from $1.77,1.72,1.70$ to 1.68 correspondingly. When magnification reaches 1000, their fractal dimensions decrease to 1.87 and 1.82 separately; when magnification is 2500 , their fractal dimensions increase to 2.17 and 2.2; when magnification increases to 5000, their fractal dimensions are 2.28 and 2.12. Red sandstone has a fluctuation pattern of "low-high-low," that is, when magnification is 500, its fractal dimensions is 1.35; when magnification reaches 1000, its fractal dimensions increase to 1.59; when magnification is 2500, its fractal dimension gets to 1.38; when magnification increases to 


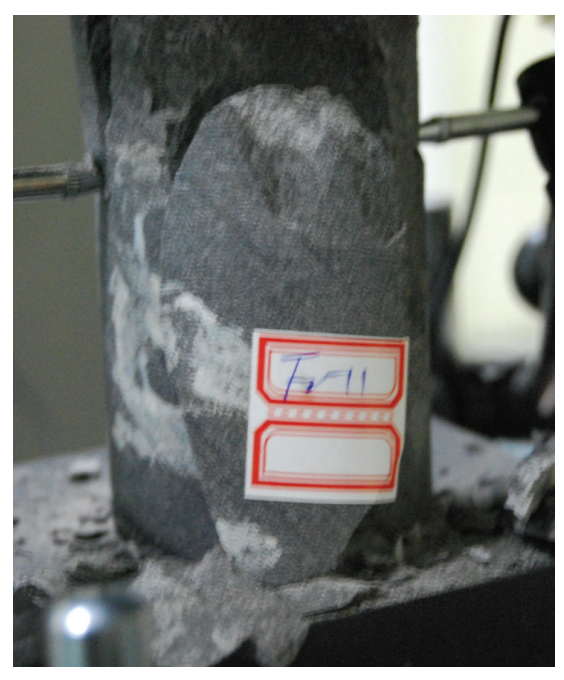

(a) Grey diabase

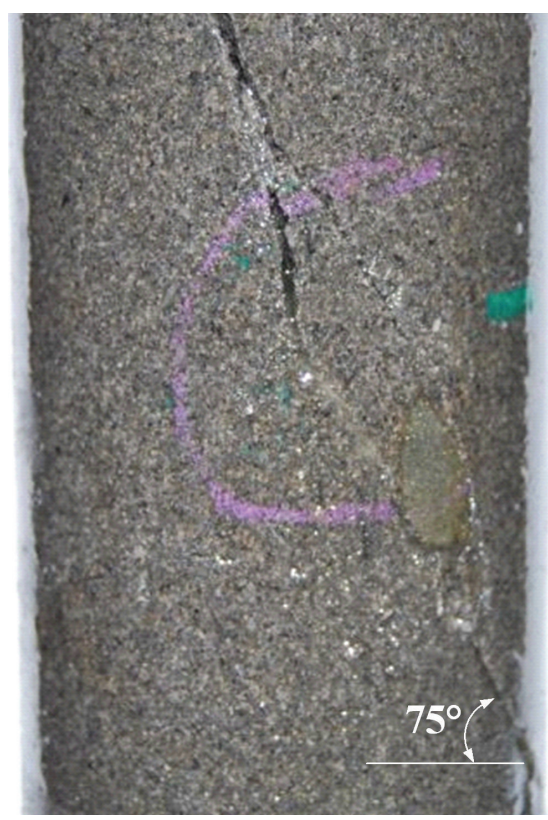

(c) Grey sandstone

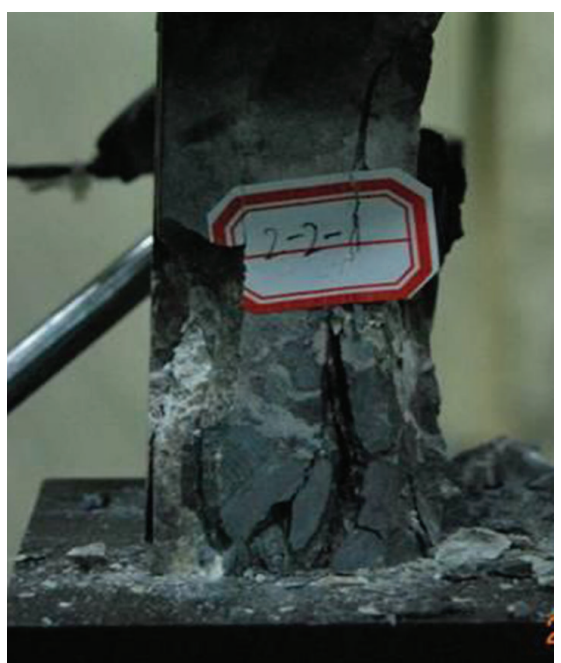

(b) Black diabase

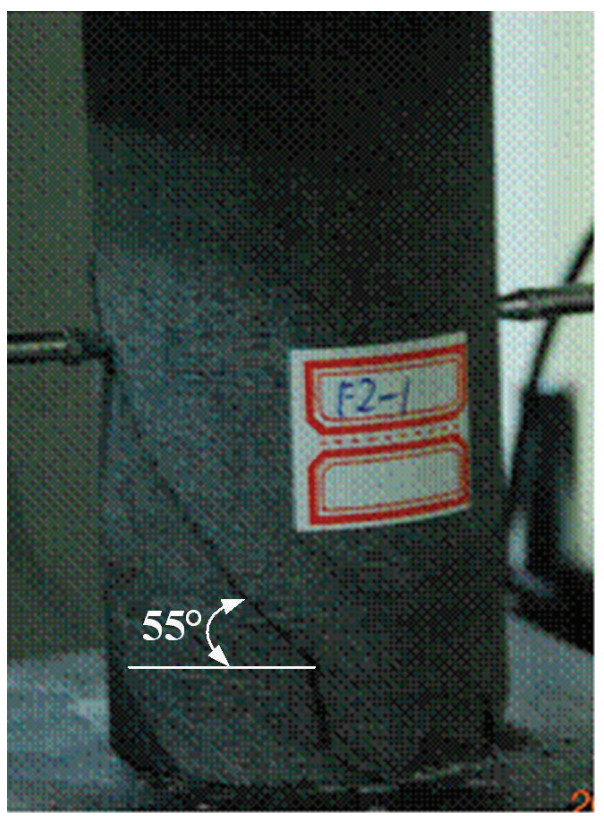

(d) Red sandstone

FIgURE 9: Rock failure patterns under uniaxial compression.

TABLE 1: Fitting results of fractal dimension for different magnification.

\begin{tabular}{lcccccccccc}
\hline \multirow{2}{*}{ Rock type } & \multicolumn{2}{c}{ Magnification 500 } & \multicolumn{2}{c}{ Magnification 1000} & \multicolumn{2}{c}{ Magnification 2500 } & \multicolumn{2}{c}{ Magnification 2500 } & \multicolumn{2}{c}{ Average } \\
& $D_{c}$ & $\mathrm{RC}$ & $D_{c}$ & $\mathrm{RC}$ & $D_{c}$ & $\mathrm{RC}$ & $D_{c}$ & $\mathrm{RC}$ & $D_{c}^{\prime}$ & $R_{c}^{\prime}$ \\
\hline Grey diabase & 1.92 & 0.87 & 1.87 & 0.82 & 2.17 & 0.91 & 2.28 & 0.95 & 2.06 & 0.89 \\
Black diabase & 1.95 & 0.89 & 1.85 & 0.80 & 2.20 & 0.90 & 2.12 & 0.93 & 2.03 & 0.88 \\
Grey sandstone & 1.77 & 0.75 & 1.72 & 0.72 & 1.70 & 0.65 & 1.68 & 0.61 & 1.72 & 0.68 \\
Red sandstone & 1.35 & 0.62 & 1.59 & 0.74 & 1.38 & 0.61 & 1.29 & 0.59 & 1.40 & 0.64 \\
\hline
\end{tabular}

5000, its fractal dimensions decrease to 1.29. Moreover, the fitted results showed related efficient (RC) has the same variation pattern with the increase of magnification (Figure 8). It is clear that the self-similarity of rock microstructure markedly changes with the scanned microscale. Different rocks behave different fractal dimension variation patterns with magnification. Grey diabase and black diabase have high suitability, red sandstone has low suitability. So the suitability of fractal dimension describing method for rocks depends on both investigating scale and rock type. 


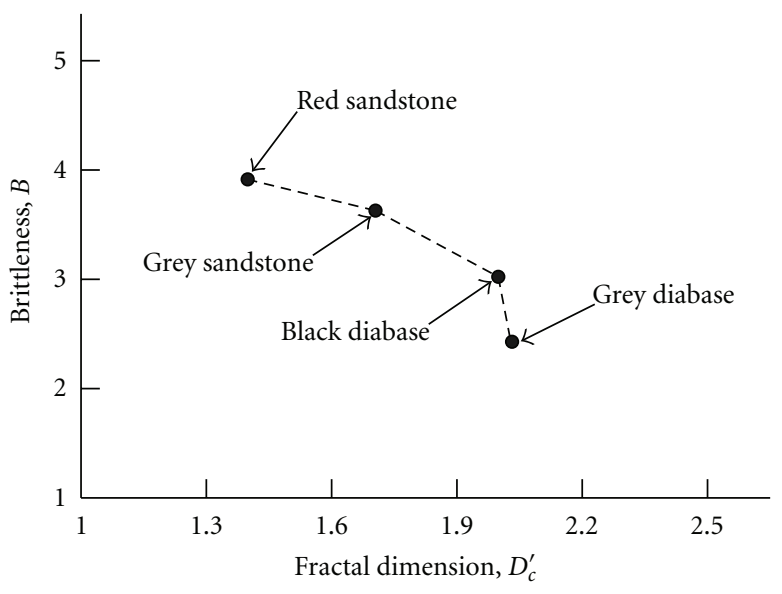

FIGURE 10: Corresponding relationship between fractal dimension and brittleness of rocks.

TABLE 2: Typical rock brittleness obtained by experiment.

\begin{tabular}{lcccc}
\hline Order & Rock type & $\sigma_{c}(\mathrm{Mpa})$ & $\sigma_{t}(\mathrm{Mpa})$ & $B$ \\
\hline $\mathrm{a}$ & Grey diabase & 127.9 & 53.3 & 2.40 \\
$\mathrm{~b}$ & Black diabase & 102.7 & 33.7 & 3.05 \\
$\mathrm{c}$ & Grey sandstone & 75.4 & 20.8 & 3.63 \\
$\mathrm{~d}$ & Red sandstone & 68.8 & 17.3 & 3.96 \\
\hline
\end{tabular}

As we know, rock is a typical inhomogeneous material. In order to investigate the macromechanical property of rock influenced by inhomogeneity, a concept named after brittleness [28] was adopted. It implies that higher brittleness represents low value of elongation, fine fracture formation, and high ratio of compressive to tensile strength. A general law with regard to brittleness is that a more brittle rock breaks at very little deformation [29]. At present, five common approaches are used to measure the brittleness value: strainbased approach [30], reversible energy-based approach [31], Mohr's envelope-based approach [25], strength ratio-based approach [32], and Protodyakonov impact test [33]. For simplicity, we adopted the strength ratio-based approach in this paper:

$$
B=\frac{\sigma_{c}}{\sigma_{t}}
$$

where $B$ is brittleness, $\sigma_{c}$ is uniaxial compressive strength, and $\sigma_{t}$ is uniaxial tensile strength.

The brittleness, $B$, was obtained by experiments, as listed in Table 2. The brittlenesses of grey diabase, black diabase, grey sandstone, and red sandstone are 2.40, 3.05, 3.63, and 3.96, separately.

Through uniaxial compression tests, we found the four kinds of stone behaved different failure patterns (Figure 9). For grey diabase and black diabase which have lower brittleness value, $B=2.4$ and $B=3.05$, cleavage crackings along axial direction happened. But for grey sandstone and red sandstone which have higher brittleness value, $B=3.63$ and $B=3.96$, main failures occurred along breaking angle, $\alpha=75^{\circ}$ and $\alpha=55^{\circ}$. Obviously, as brittleness value, $B$, increases, the rock failure angle decreases. As we know, the rock failure angle, $\alpha=45^{\circ}+\varphi / 2$, where $\varphi$ is the internal friction angle of rock. So the higher homogeneity of rock is, the closer particles inner rock coheres, and the lager internal friction angle is.

Comparing estimated fractal dimension with brittleness of above four kind rocks, we found that the less the rock brittleness is, the larger the rock profile fractal dimension is, as shown in Figure 10. In situ investigations showed the high homogeneous grey diabase has an intense rock burst tendentiousness, the less high homogeneous black diabase has a feeble rock burst tendentiousness, but the inhomogeneous grey sandstone and red sandstone have no rock burst tendentiousness. In a sense, brittleness, $B$, is a map of rock macromechanical property arising from inhomogeneity, while fractal dimension of microstructure on rock profile is an image of inhomogeneous microstructure distribution of rock in a sense. Thus, for the rocks which have high self-similarity in microscale, we can combine the fractal dimension of profile and brittleness to investigate their failure mechanism, pattern, and behaviours.

\section{Conclusions}

The aim of the laboratory SEM scanning tests and fractal dimension estimation was to identify the influence of microstructure inhomogeneity on rock mechanical property. By comparing with the past investigation, this research contains at least three original aspects.

(1) The SEM tests on microstructure inhomogeneity and fractal dimension estimation of four type rocks were performed.

(2) The differences of self-similarity of microstructures for different rocks were investigated primarily.

(3) The relation between rock profile fractal dimension and rock brittleness influenced by different inhomogeneities was obtained.

The investigations showed the following.

(1) The self-similarity of rock microstructure markedly changes with the scanned microscale. Different rocks behave different fractal dimension variation patterns with the change of magnification. So it is conditional to adopt fractal dimension to describe rock material. It is suitable for some rocks, but it is not suitable for some other rocks. For instance, grey diabase and black diabase have high suitability, and red sandstone has low suitability. The suitability of fractal dimension describing method for rocks depends on both investigating scale and rock type.

(2) The homogeneities of grey diabase, black diabase, grey sandstone, and red sandstone are 7.8, 5.7, 4.4, and 3.4, separately; their average fractal dimensions of microstructure are 2.06, 2.03,1.72, and 1.40, correspondingly, so the homogeneity is well consistent with fractal dimension. 
(3) The brittleness of black diabase, grey diabase, grey sandstone, and red sandstone are 2.40, 3.05, 3.63, and 3.96, separately. For rock material, the stronger brittleness is, the less profile fractal dimension is. In a sense, brittleness is an image of rock inhomogeneity in macro-scale, while profile fractal dimension is an image of rock inhomogeneity in microscale.

(4) To combine the test of brittleness with the estimation of fractal dimension with condition will be an effective approach for understanding rock failure mechanism, patterns, and behaviours.

\section{Acknowledgments}

This work was supported in part by the National Basic Research Program of China (973 Program) Grant No. 2010CB226805, China Natural Science Fund (no. 51074099, no. 51004068), and SDUST Research Fund (no. 2010KYTD105).

\section{References}

[1] Y. J. Wei and L. Anand, "Grain-boundary sliding and separation in polycrystalline metals: application to nanocrystalline fcc metals," Journal of the Mechanics and Physics of Solids, vol. 52, no. 11, pp. 2587-2616, 2004.

[2] S. Zabler, A. Rack, I. Manke et al., "High-resolution tomography of cracks, voids and micro-structure in greywacke and limestone," Journal of Structural Geology, vol. 30, no. 7, pp. 876-887, 2008.

[3] H. P. Xie and F. Gao, "The mechanics of cracks and a statistical strength theory for rocks," International Journal of Rock Mechanics and Mining Sciences, vol. 37, no. 3, pp. 477488, 2000.

[4] Y. Guéguen, T. Chelidze, and M. Le Ravalec, "Microstructures, percolation thresholds, and rock physical properties," Tectonophysics, vol. 279, no. 1-4, pp. 23-35, 1997.

[5] T. I. Chichinina and I. R. Obolentseva, "Seismic gyrotropy as a result of rock-microstructure dissymmetry," Theoretical and Applied Fracture Mechanics, vol. 30, no. 3, pp. 251-265, 1998.

[6] G. E. Exadaktylos and I. Vardoulakis, "Microstructure in linear elasticity and scale effects: a reconsideration of basic rock mechanics and rock fracture mechanics," Tectonophysics, vol. 335, no. 1-2, pp. 81-109, 2001.

[7] M. H. B. Nasseri and B. Mohanty, "Fracture toughness anisotropy in granitic rocks," International Journal of Rock Mechanics and Mining Sciences, vol. 45, no. 2, pp. 167-193, 2008.

[8] J. Takadoum and H. Houmid Bennani, "Influence of substrate roughness and coating thickness on adhesion, friction and wear of TiN films," Surface and Coatings Technology, vol. 96, no. 2-3, pp. 272-282, 1997.

[9] M. H. Nasseri, K. S. Rao, and T. Ramamurthy, "Failure mechanism in schistose rocks," International Journal of Rock Mechanics and Mining Sciences \& Geomechanics Abstracts, vol. 34, no. 3-4, p. 460, 1997.

[10] S. Raynaud, G. Vasseur, B. Célérier et al., "Experimental study of the relation between the permeability of kaolinite and its deformation at micro and macro scale," International Journal of Rock Mechanics and Mining Sciences, vol. 47, no. 4, pp. 559567, 2010.
[11] H. Alkan, "Percolation model for dilatancy-induced permeability of the excavation damaged zone in rock salt," International Journal of Rock Mechanics and Mining Sciences, vol. 46, no. 4, pp. 716-724, 2009.

[12] T. I. Chichinina and I. R. Obolentseva, "Seismic gyrotropy as a result of rock-microstructure dissymmetry," Theoretical and Applied Fracture Mechanics, vol. 30, no. 3, pp. 251-265, 1998.

[13] B. B. Mandelbrot, Fractal Geometry of Nature, Freeman, San Francisco, Calif, USA, 1982.

[14] A. P. Pentland, "Fractal-based description of natural science," IEEE Transactions on Pattern Analysis and Machine Intelligence, vol. 6, no. 6, pp. 661-674, 1984.

[15] J. J. Gagnepain and C. Roques-Carmes, "Fractal approach to two-dimensional and three-dimensional surface roughness," Wear, vol. 109, no. 1-4, pp. 119-126, 1986.

[16] J. M. Keller, S. Chen, and R. M. Crownover, "Texture description and segmentation through fractal geometry," Computer Vision, Graphics and Image Processing, vol. 45, no. 2, pp. 150166, 1989.

[17] N. Sarkar and B. B. Chauduri, "Efficient differential boxcounting approach to compute fractal dimension of image," IEEE Transactions on Systems, Man and Cybernetics, vol. 24, no. 1, pp. 115-120, 1994.

[18] A. K. Bisoi and J. Mishra, "On calculation of fractal dimension of images," Pattern Recognition Letters, vol. 22, no. 6-7, pp. 631-637, 2001.

[19] C. A. Pickover and A. Khorasani, "Fractal characterization of speech waveform graphs," Computers and Graphics, vol. 10, no. 1, pp. 51-61, 1986.

[20] S. S. Chen, J. M. Keller, and R. M. Crownover, "On the calculation of fractal features from images," IEEE Transactions on Pattern Analysis and Machine Intelligence, vol. 15, no. 10, pp. 1087-1090, 1993.

[21] N. Sarkar and B. B. Chaudhuri, "An efficient approach to estimate fractal dimension of textural images," Pattern Recognition, vol. 25, no. 9, pp. 1035-1041, 1992.

[22] S. Ge and S. Suo, "Computation methods for fractal dimension of surface profile," Mocaxue Xuebao/Tribology, vol. 17, no. 4, pp. 354-362, 1997.

[23] L. He and J. Zhu, "The fractal character of processed metal surfaces," Wear, vol. 208, no. 1-2, pp. 17-24, 1997.

[24] C. Q. Yuan, J. Li, X. P. Yan, and Z. Peng, "The use of the fractal description to characterize engineering surfaces and wear particles," Wear, vol. 255, no. 1-6, pp. 315-326, 2003.

[25] Z. Yue, "Digital representation of meso-geomaterial spatial distribution and associated numerical analysis of geomechanics: methods, applications and developments," Chinese Journal of Rock Mechanics and Engineering, vol. 25, no. 5, pp. 875-888, 2006.

[26] C. X. Chen, X. M. Liu, and C. H. Liu, "Application of digital image processing to rock mesomechanics," Rock and Soil Mechanics, vol. 31, no. 1, pp. 53-61, 2010.

[27] Y. L. Tan, C. X. Liu, and T. B. Zhao, Elementary Theory for Rock Nonlinear Dynamics, Coal Industry Publishing House, Beijing, China, 2008.

[28] V. Hucka and B. Das, "Brittleness determination of rocks by different methods," International Journal of Rock Mechanics and Mining Sciences \& Geomechanics Abstracts, vol. 11, no. 10, pp. 389-392, 1974.

[29] Q. M. Gong and J. Zhao, "Influence of rock brittleness on TBM penetration rate in Singapore granite," Tunnelling and Underground Space Technology, vol. 22, no. 3, pp. 317-324, 2007. 
[30] E. A. George, Brittle Failure of Rock Material-Test Results and Constitutive Models, A.A. Balkema Publishers, Rotterdam, The Netherlands, 1995.

[31] A. A. Vihtuk, "Determination of strength of solid porous body," Acta Physica Polonica A, vol. 93, pp. S-71-S-78, 1998.

[32] S. Kahraman, "Correlation of TBM and drilling machine performances with rock brittleness," Engineering Geology, vol. 65, no. 4, pp. 269-283, 2002.

[33] M. M. Protodyakonov, "Mechanical properties and drillability of rocks," in Proceedings of the 5th Symposium Rock Mechanics, pp. 103-118, University of Minnesota, 1963. 

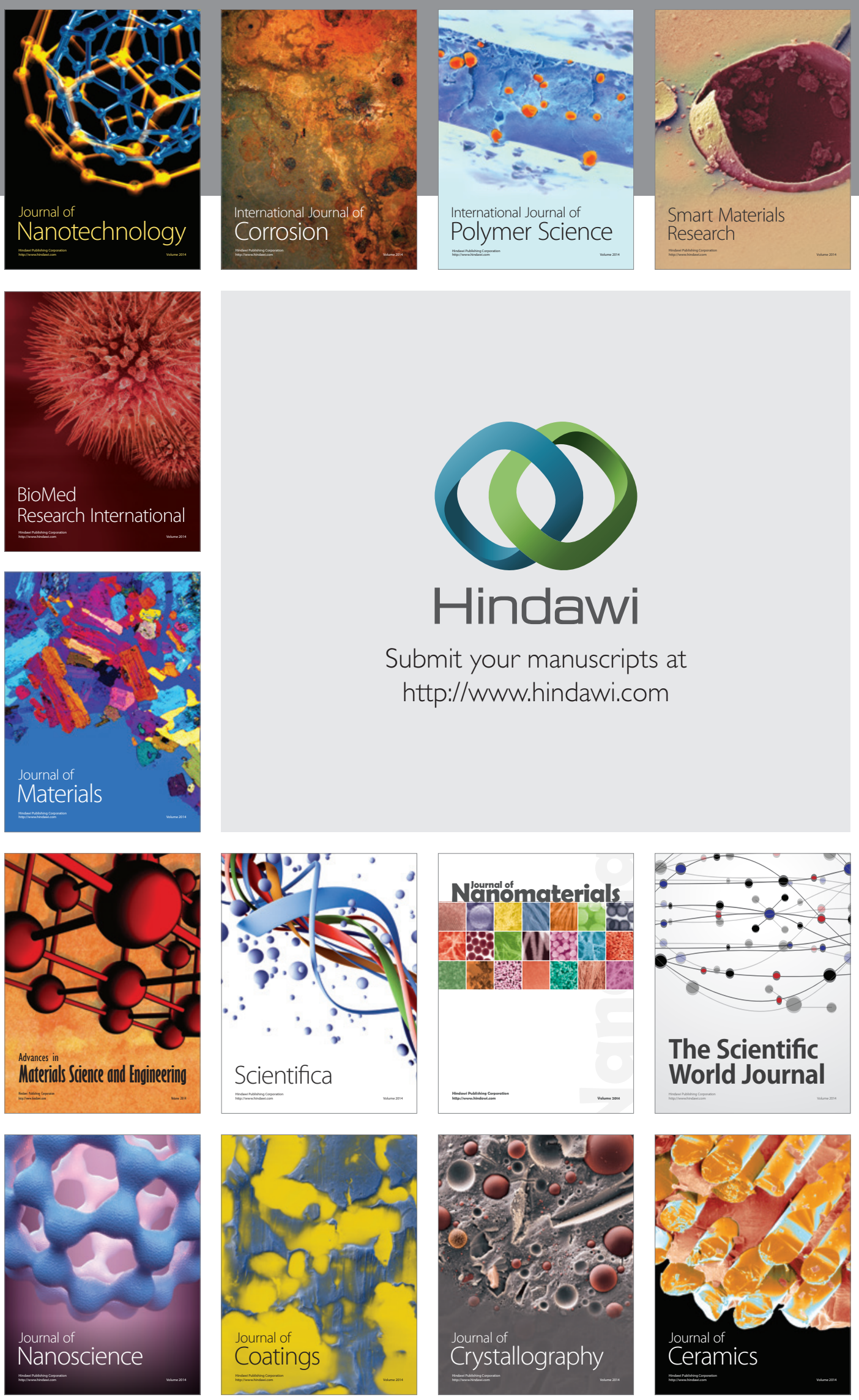

The Scientific World Journal

Submit your manuscripts at

http://www.hindawi.com

\section{World Journal}

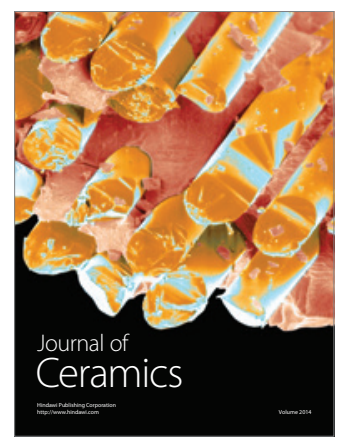

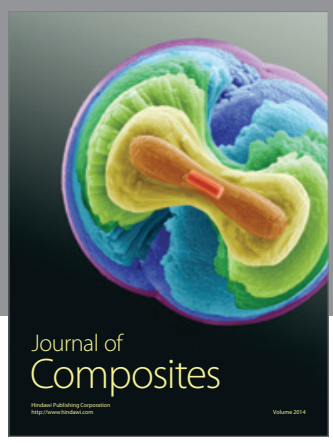
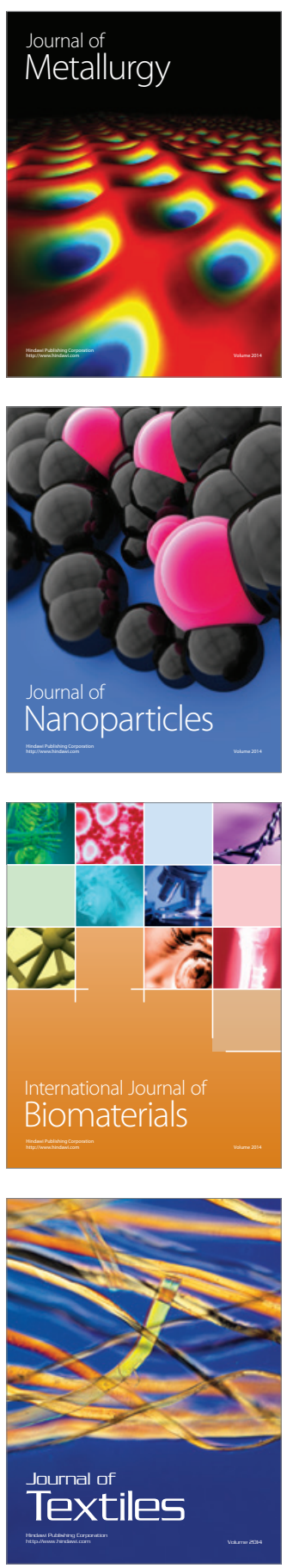